\title{
Low Concentration Gas Measurement Using Photonic Bandgap Fiber Cell Sensor
}

\author{
Joanna Pawłat Non-member (Waseda University, askmik@hotmail.com) \\ Tadashi Sugiyama Non-member (Yokogawa Electric Corporation) \\ Xuefeng Li Non-member (Waseda University) \\ Takahiro Matsuo Student Member (Waseda University) \\ Satoshi Ikezawa Student Member (Waseda University) \\ Toshitsugu Ueda Member (Waseda University)
}

Keywords : low gas concentration sensing, photonic bandgap fiber, microcapillary gas flow

A high-sensitivity, compact set-up, which enables the precise measurement of low concentration of gas, was developed. The spectroscopic measurements were performed inside the Photonic Bandgap Fibers, which were designed especially for this research purpose and functioned as the gas cells of the apparatus (Fig. 1). Proposed technique allowed to reduce the total size of the set-up (portability) and the gas sample volume to $0.01 \mathrm{cc}$. In the case of fibers' mass production, presented research project will result in low cost, high-sensitivity, real-time measurement system.

Ammonia absorption spectrum shows several peaks around 1500-2000 nm wavelength. Thus, $1550 \mathrm{~nm}$ emission wavelength tunable laser was chosen for the optical measurement system. The emitted laser light, which wavelength corresponded to the absorption wavelength of the pollutant molecule was partly absorbed by the ammonia gas within the optical fiber. The absorption was strictly related to the concentration of $\mathrm{NH}_{3}$ in the carrying gas (high-purity nitrogen). For testing of newly designed fibers' (1960 nm centre operating wavelength), the set-ups with LED lamps and Oriel Fiber Illuminator with xenon lamp were used. The core diameters of produced fibers used in the experiment were: $16.2 \mu \mathrm{m}, 19.4 \mu \mathrm{m}, 19.9 \mu \mathrm{m}$ and $26.25 \mu \mathrm{m}$. Core diameter could be increased through careful removal of cladding bars located in the centre of fiber during the technological process. Alternatively, $700 \mu \mathrm{m}$ core, multimode holey fibers were tested. Lowering the pressure in the gas cell allowed to obtain clear absorption peaks and to classify investigated molecules. HITRAN simulation of light absorption by pollutant's molecules in selected concentration and BANDSOLVE simulations of light guiding

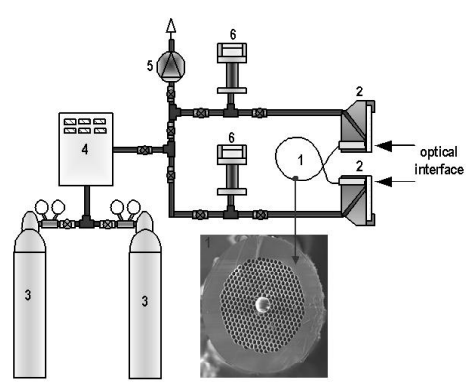

1- PBGF cell, 2- gas dosing cell, 3- gas tank, 4- gas mixing device, 5rotary pump, 6- pressure control

Fig. 1. Scheme of gas-providing sub-system process within fiber were performed. To achieve sub-ppb sensitivity with signal, which is detectable for common optical receivers; 3-10 meters of fiber was required. Ppm level measurements involved relatively shorter fiber.

Microcapillary nitrogen gas flow simulations were performed employing quasi-Panhandle equation for modeling of the compressible fluid flow. The results were confirmed by experimental work, and are depicted in Fig. 2.

As it was necessary to precisely introduce both: gas and light into the fiber's core, the new method of fiber cutting using Cross Section Polisher (Ar ion beam in the vacuumed chamber) was tested to obtain required angle of fiber (Fig. 3).

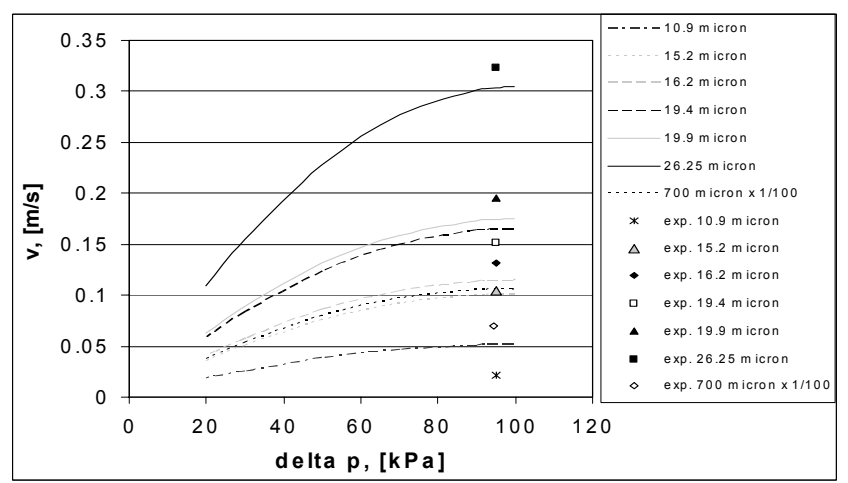

Fig. 2. Simulations of gas velocity and experimental results (700 microns core- $4 \mathrm{~m}$ length and 10.9-26.25 micron core $-0.2 \mathrm{~m}$ length)
A

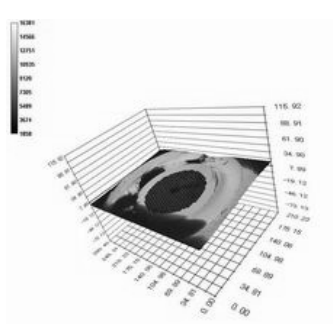

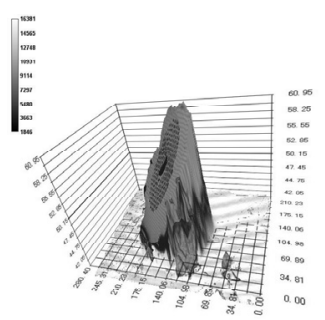

Fig. 3. Laser microscope 3D photo of PBG fiber. Standard fiber-cutter (A) and Cross Section Polisher cutting (B) 


\section{Low Concentration Gas Measurement Using Photonic Bandgap Fiber Cell Sensor}

$\begin{array}{ll}\text { Joanna Pawłat* } & \text { Non-member } \\ \text { Tadashi Sugiyama*** } & \text { Non-member } \\ \text { Xuefeng Li* } & \text { Non-member } \\ \text { Takahiro Matsuo* } & \text { Student Member } \\ \text { Satoshi Ikezawa* } & \text { Student Member } \\ \text { Toshitsugu Ueda* } & \text { Member }\end{array}$

Among few existing applications of Microstructured Optical Fibers, a new device for measurement of low gas concentration was designed. Developed set-up based on a Photonic Bandgap Fiber (PBGF), which was used as a gas cell. Proposed technique allowed reducing gas sample volume to $0.01 \mathrm{cc}$. The gas flow inside core of fiber was simulated and result was confirmed experimentally. During the experimental work several types of fibers of various parameters were specially designed, produced and used. Core diameters ranged from $10.9 \mu \mathrm{m}$ to $700 \mu \mathrm{m}$. Various cutting techniques for fibers were investigated.

Keywords : low gas concentration sensing, photonic bandgap fiber, microcapillary gas flow

\section{Introduction}

There are several types of Microstructured Optical Fibers (MOFs), which differ in structure and wave-guiding mechanism. The most general classification can be summarized as follows $^{(1)-(5)}$ :

-Photonic Crystal Fibers (PCFs) with solid core surrounded by air holes cladding structure. PCFs can operate on the same principle as the conventional optical fibers: total internal reflection, which is achieved due an increased refractive index of the fiber's core.

-Bragg Fibers, which confine the light through photonic-bandgap in a relatively large diameter hollow core formed by the concentric rings of multilayer films of different materials.

-Photonic Bandgap Fibers (PBGFs) of a honeycomb structure with a hollow core surrounded by the highly regular microstructured cladding.

Present need for the fast, proper and accurate measurement of various compounds in ppb levels encouraged our research group to engage in the development of a new sensing system. Huge possibilities of new in-situ measurement method were revealed during preliminary research using tunable laser and glass or metal tanks $^{(6)-(8)}$ and the $\mathrm{PBGF}^{(9)-(11)}$ as the gas cells. This paper reports conducted work, focusing on investigation of the micro-capillary gas flow phenomenon inside fiber, and also covering examination of properties of photonic bandgap fiber, the design of the proper fibers for our device and study on the low concentration gas measurement system for the semiconductor manufacturing industry. The first results of ammonia $\left(\mathrm{NH}_{3}\right)$ concentration

* Graduate School of IPS, Waseda University. 808-0135 Fukuoka ken, Kitakyushu-shi, Wakamatsu-ku, 2-7 Hibikino

** Yokogawa Electric Corporation, 180-8750, Tokyo, 2-9-32 Naka-cho, Musashino-shi measurements are shown. Shaping of the end of fiber is necessary to assure the proper input of light into the PBGF's core. Traditional cutting methods used in the case of communication optical fibers destroy the fragile cladding structure.

Cutting using Cross Section Polisher was proposed as non destructive and precise technique.

\section{Experimental Set Up}

The system consisted of 3 sub-systems: gas providing sub-system, optical sub-system, chemical analysis sub-system and optical fiber as a main measuring cell.

One of the goals of research work was to design a set-up measuring low concentration of ammonia after further dilution of few ppm- gas with high purity nitrogen even to ppb level.

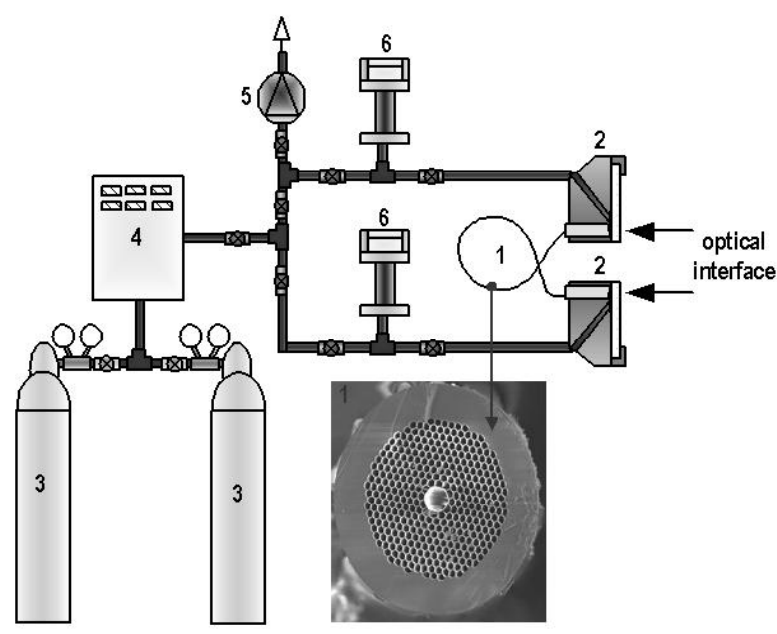

(1- PBGF, 2- gas cell, 3- gas tank, 4- gas mixing device, 5- rotary pump, 6- pressure control)

Fig. 1. Scheme of gas-providing sub-system 
Gas was dosed into the gas cell of special design and it passed throughout the optical fiber for proper measurement of light absorption.

The gas- providing system is presented in Fig. 1. Both ends of fiber were connected to the rotary pump and slight pressure difference was kept between them to assure the gas flow.

The PBGFs had the unique structure, and light was mostly guided in a hollow, circular core surrounded by a microstructured cladding formed by a periodic arrangement of air holes in undoped silica. Up to $65 \%$ of the fiber cross-section was composed of solid silica but less than $5 \%$ of light propagated in glass. More than $90 \%$ of optical power was located in the hollow core or in the holes of cladding. Holes of core and cladding were filled with the tested gas. Fiber was coated with a single acrylate layer. Centre operating wavelength of fiber matched the emission wavelength of light source and the absorption band of analyzed pollutants.

$1550 \mathrm{~nm}$ emission wavelength tunable laser was chosen for the optical measurement system using commonly produced PBGF. Light passed objective lens, the zero-order waveplate and was split using cube beam splitter. The output light was guided inside the optical fiber from and to the gas cells, and passed objective lens with the zero-order waveplate. Finally, both: measurement light wave front and reference light wavefront (adjusted using mirror) were received by two photodetectors. The optical system with laser is depicted in Fig. 2A.

The coupling of the light depends on the light source and fiber's bandwidth.

As ammonia emission reveals high peak around $1.9 \mu \mathrm{m}$, and the size of the core was crucial to the gas flow, the PBGFs of such light guiding center were designed using BandSolve (CAD alike

A

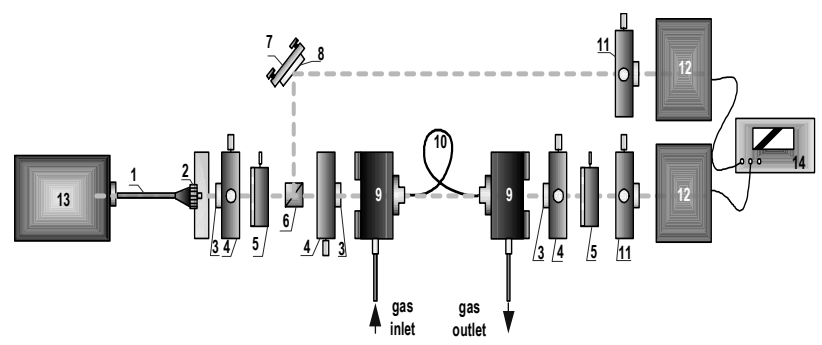

1- optical fiber, 2- optical fiber connector FC, 3- objective lens with adapter, 4, 11- stage, 5 - rotary stage with zero-order wave plate, 6 - beam splitter, 7, 8- mirror unit, 9- gas cell, 10- photonic bandgap fiber, 12photodetector, 13-tunable laser, 14-differential amperometer.

B

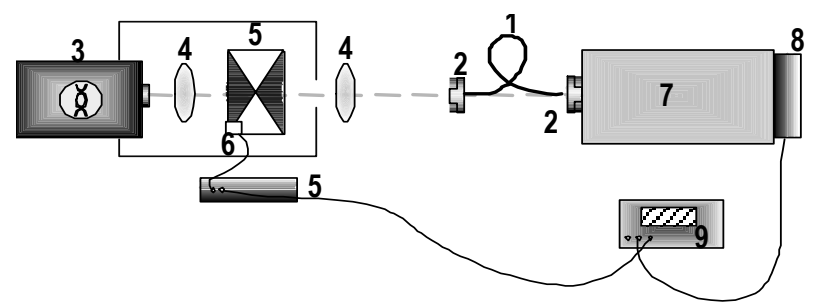

1-photonic crystal fiber, 2- fiber adapter, 3- lamp, 4- quartz glass objective lenses with adapters, 5- chopper with power supply, 6opto-couple, 7-Oriel IR monochrometer (MS 260), 8- photodetector (EG\&G MSD1), 9- NF lock-In amplifier (LI 570 A)

Fig. 2. Schemes of optical subsystem with laser (A) and lamp (B). commercially available design tool to optimize the band structure of new photonic crystal geometries before fabricating the device) and other simulation software and made by stack-and-draw technique $^{(12)(13)}$. For measurement of newly designed fibers' properties at 1.5 and $1.9 \mu \mathrm{m}$, the set-ups with LED lamps and Oriel Fiber Illuminator with xenon lamp were used. The working scheme of optical sub-system with lamp is depicted in Fig. 2B. Light, which was emitted by above sources, passed through chopper unit, focusing lenses and was guided to monochrometer. Light of certain wavelength was detected using wide-wavelength GaInAs pin photodiode. Signals from photodiode and chopper were adjusted, amplified and observed using digital oscilloscope.

The emitted light, which wavelength corresponded to the absorption of ammonia molecule should be partly absorbed by the gas within the optical fiber. The absorption would be then strictly related to the concentration of ammonia in the carrying gas (high-purity nitrogen).

The core diameters of new fibers used in the experiment were: $15.2 \mu \mathrm{m}, 16.2 \mu \mathrm{m}, 19.4 \mu \mathrm{m}, 19.6 \mu \mathrm{m}$ and $26.25 \mu \mathrm{m}$. Additionally, $10.9 \mu \mathrm{m}$ core fiber, produced by Blaze Photonics and available on the market was tested. Table 1 contains characteristics and SEM photos of all used fibers.

The matching comparison of simulated light absorption by ammonia molecule with available LED parameters and bandgap boundaries of designed fiber are presented in Fig. 3 and Fig. 4. According to HITRAN ${ }^{(14)}$ simulations to measure the ppb level of ammonia, several meters of fiber are required, to ppm level- less than 1 meter would be enough.

The absorption of ammonia at the microcapillary wall was not considered. The absorption in the pure nitrogen should not occur, however the fix considering absorption of ammonia at highly

Table 1. Fibers used in the experiment.

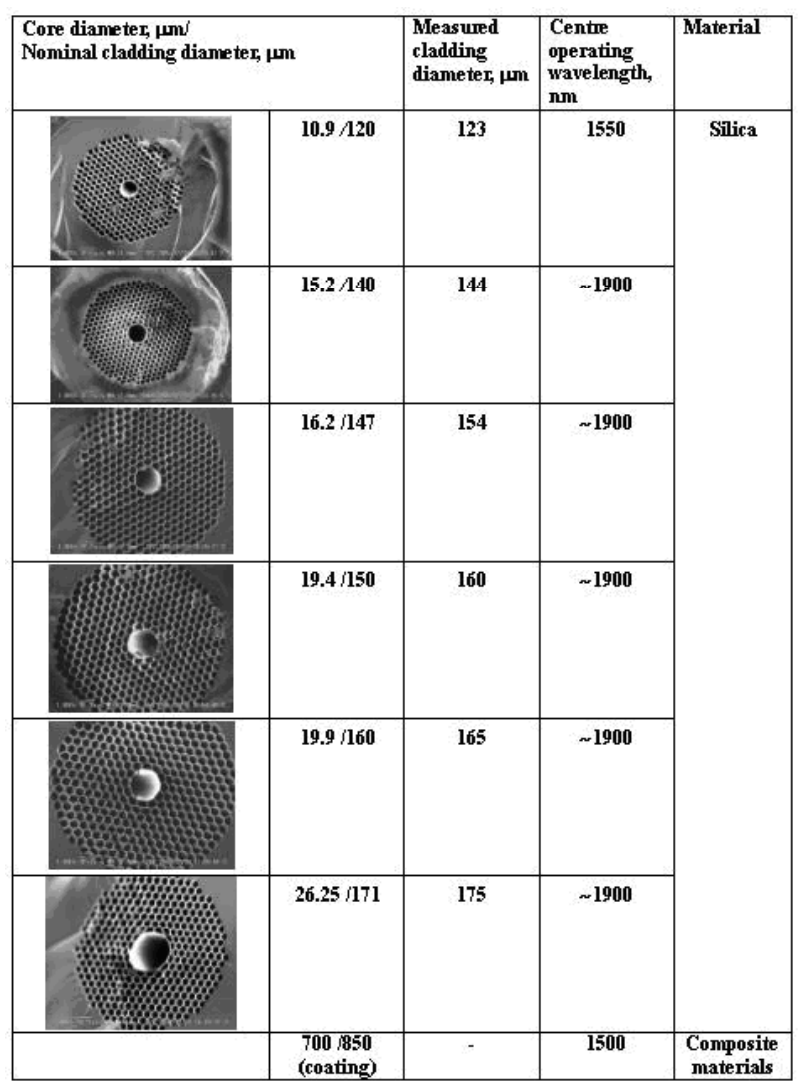


absorptive material: silica for the real case measurement will be developed in the future.
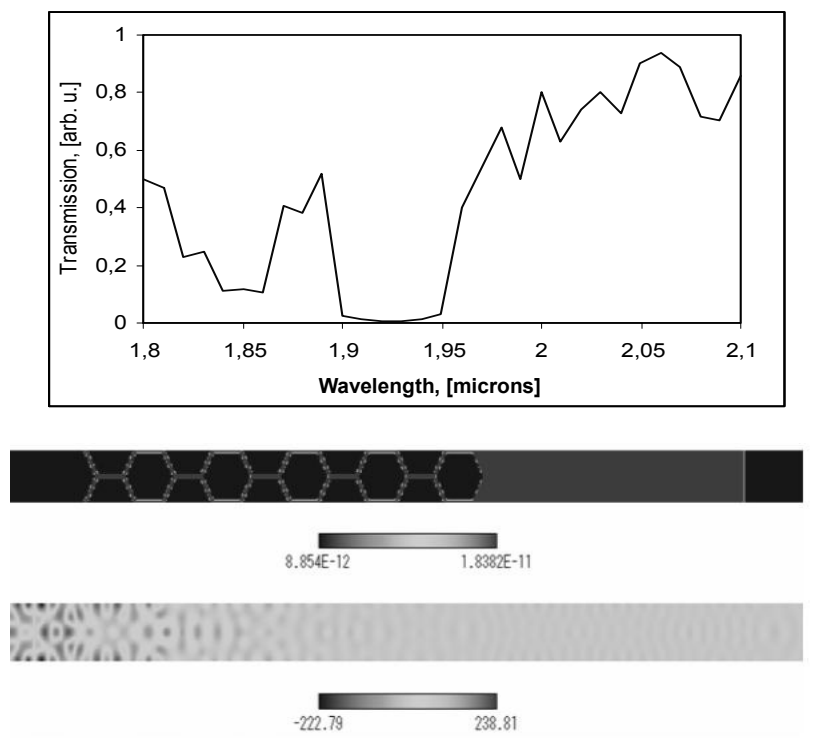

Fig. 3. The bandgap characteristics of $26.25 \mu \mathrm{m}$ core fiber $\left(\lambda=1.936, \quad \mathrm{n}=1.439\right.$, transmission $=6.639 \mathrm{e}^{-3}$ $(0.6 \%))$.

A

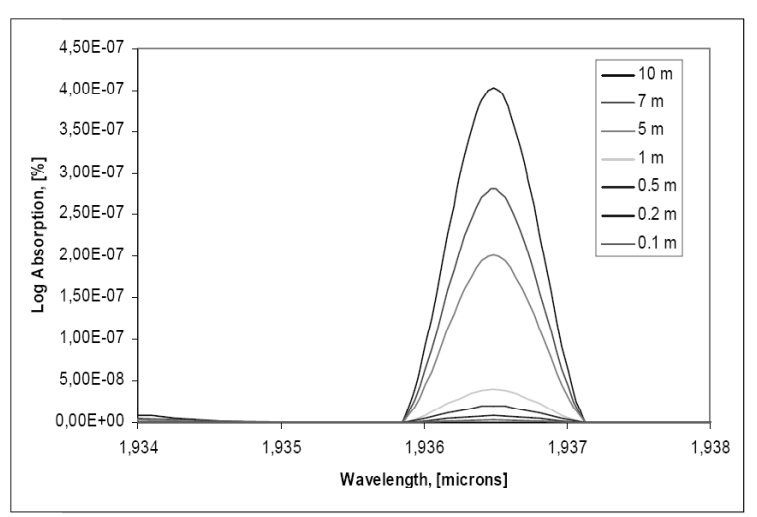

B

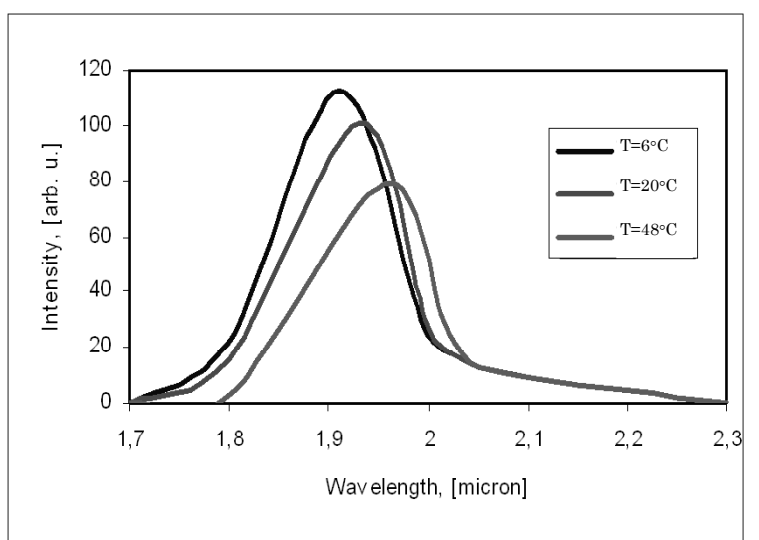

Fig. 4. HITRAN simulation of light absorption in dependence on the length of optic fiber (sub-ppb ammonia, $0.1 \mathrm{~atm})$ (A) and used light emitting diode (LED-19 type): spectral irradiances dependent on the temperature (B).
Lowering the pressure enables sharpening of absorption peaks. Thus, peaks caused by the molecules of chosen pollutant can be distinguished from the other eventual contaminants.

Microcapillary nitrogen gas flow simulations were performed employing the standard mathematical software. Velocity of the gas was calculated using quasi-Panhandle equation (1) for modeling of the compressible fluid flow:

$$
p_{1}^{2}-p_{2}^{2}=G^{2} R T / F^{2}\left(\lambda(l / d)+2 \log _{e}\left(v_{2} / v_{1}\right)\right)
$$

$p_{1}$ and $p_{2}$ are inlet and outlet pressures, G- mass flow, Rindividual gas constant, $\mathrm{T}$ - temperature, $\mathrm{F}$ - core cross-section area, $v_{1}$ and $v_{2}$ - inlet and outlet velocities, $\lambda$ - coefficient, which depends on Reynolds number.

Detailed calculation procedure for the microcapillary gas flow within the PBGF was discussed elsewhere ${ }^{(15)(16)}$.

As presented in Figs. 5-6 predicted gas flows were confirmed by the experimental results. It was possible to indirectly measure the flow rate of nitrogen gas inside the PBGF with various pressure differences on the opposite ends. In the case of $1 \mathrm{~m}$ fiber the measurement including filling time would take about 10-15 min. According to the simulation result for $0.2 \mathrm{~m}$ length of 19.4 $\mu \mathrm{m}$ core fiber, the velocity ranged $0.164 \mathrm{~m} / \mathrm{s}$. Velocity confirmed experimentally was $0.151 \mathrm{~m} / \mathrm{s}$. The volume of gas present in the system outside the fiber was calculated as precisely as possible, however, the difference between gas volume present in piping, valves and pressure gauges, and the gas volume inside the core of

$\mathbf{A}$

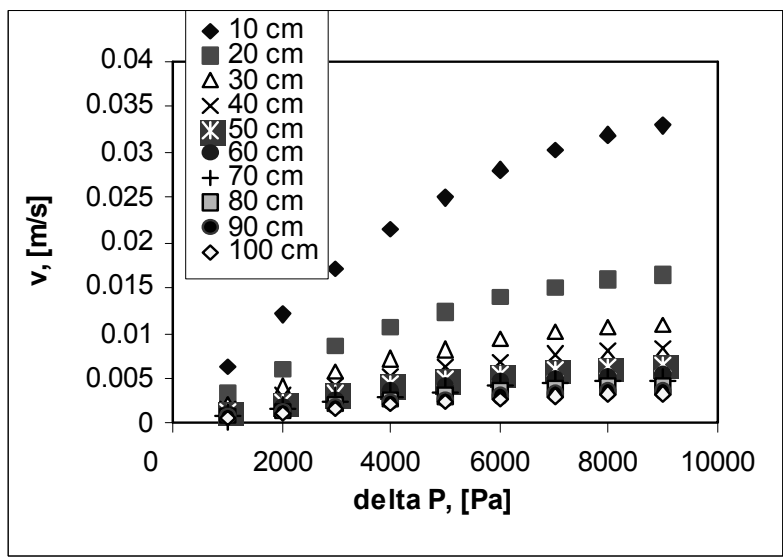

B

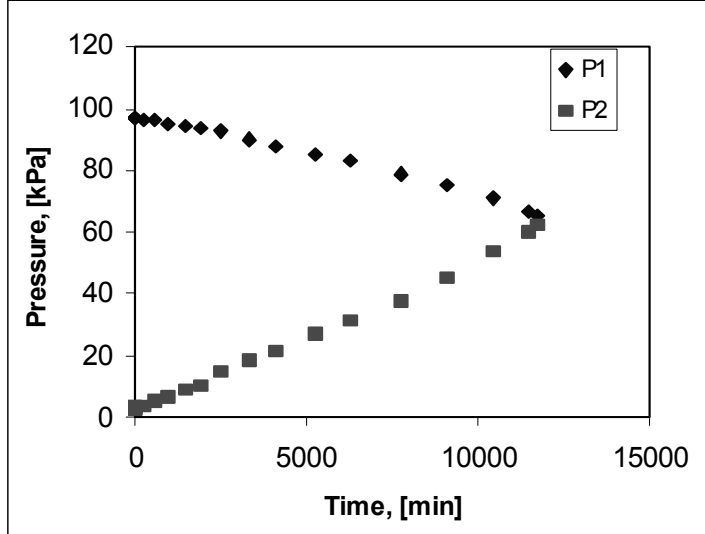

Fig. 5. Simulations of gas velocity for 19.4 micron fiber (A) and experimental results of pressure balancing for 0.2 length of 19.4 micron fiber (B). 


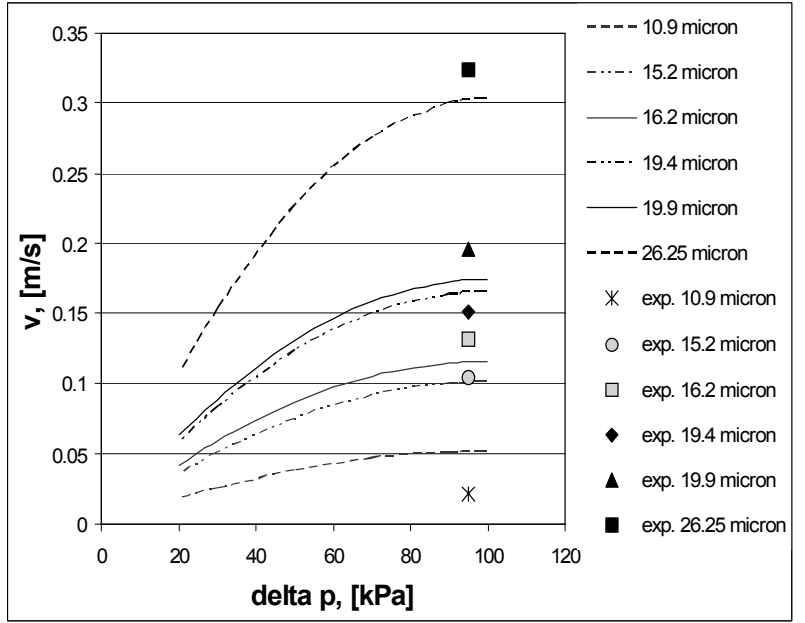

Fig. 6. Simulations of gas results (10.9-26.25 micron covelocity and experimental re $-0.2 \mathrm{~m}$ length).

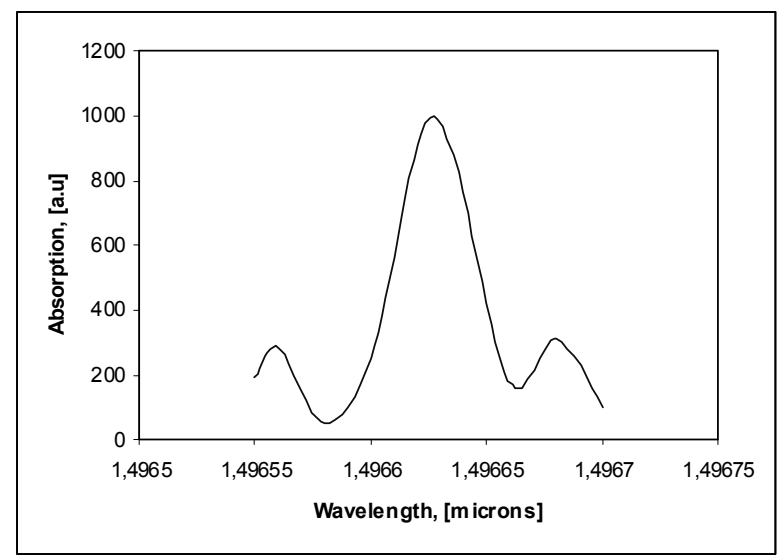

Fig. 7. Measured $10 \mathrm{ppm}$ ammonian peak.

the fiber was huge. That might explain slight differences between simulation and experimental values.

The results of ammonia concentration measurement using $1 \mathrm{~m}$ length PBGF of $10.9 \mu \mathrm{m}$ core and tunable laser are shown in Fig. 7. The ammonia measurement was performed at $0.1 \mathrm{~atm}$ average pressure. The PBGFs core volume ranged $8 \times 10^{-5} \mathrm{cc}$ and ammonia concentration in the nitrogen gas was $10 \mathrm{ppm}$. The basic peak well matched the results obtained with HITRAN simulation, however during the measurement of ammonia concentration strong side wings next to the absorption peak (not present in the simulation output graph) were observed. The phenomenon might result from the light reflection caused by the straight cut of the ends of the fiber, which was used during the experiment, from noise or less probably from the presence of some impurities.

Maximum theoretical sensitivity, which could be attained using the present set-up configuration ranged $0.18 \mathrm{ppb} / \mathrm{m}$. Total sensitivity of the device increased with fiber's length.

Avoiding the pollution and the proper cutting of PBGF had a crucial importance for the experiment. After removal of the coating, length of fiber was adjusted using several methods. The best results were obtained using Cross Section Polisher, SM-09010 (Nihon Denshi) using argon ion beam, the method well recognized in preparation of fine microscopic samples ${ }^{(17)}$. This procedure assured shaping of the end to the required angle and minimized destruction of surface part of cladding. Traditional
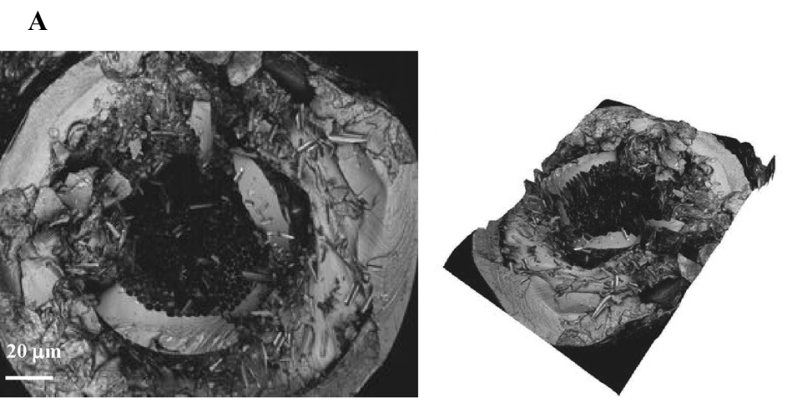

B
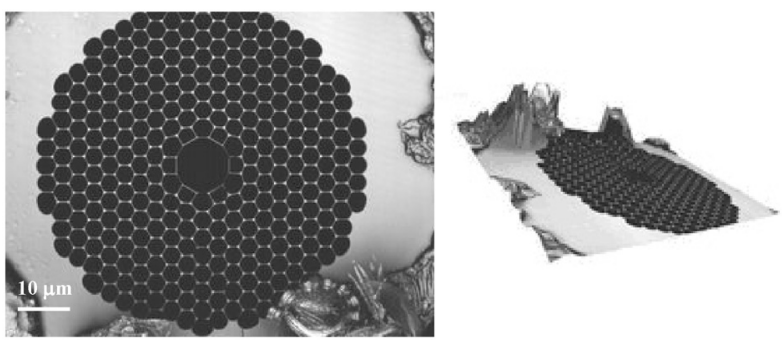

C
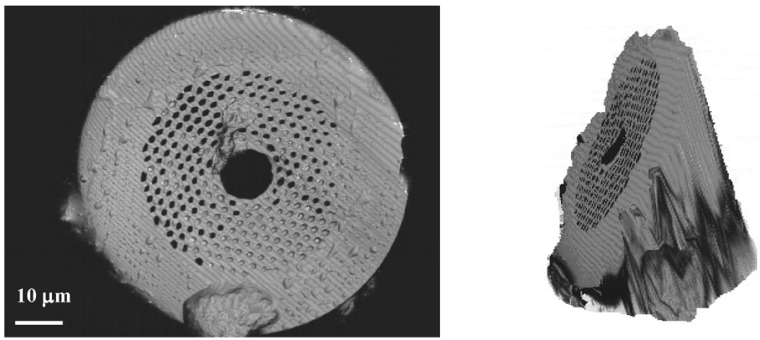

Fig. 8. Comparison of PBGF cutting methods: cutter (A), fiber cleaver (B) and Cross Section Polisher (C); laser microscope.

fiber cleaver besides lower precision allowed for only one cutting angle. The laser microscope photographs of cutting results are presented in Fig. 8. Right column represents the $3 \mathrm{D}$ profile of the surface cut. Cutting using Cross Section Polisher could be especially advantageous for precise input of the light into the fiber's core and for preventing the surface reflections, which influence the measurement spectra.

\section{Conclusions}

The set-up for measuring of ppb concentration of ammonia was designed.

New types of PBGFs were produced. Simulations of gas velocity in dependence on applied pressure were performed.

Gas flow rate in the experimental condition was corresponding to the simulated one. It was sufficient for fast ppm-order measurement using short optic fibers as the gas cells. First experiments of measurement ammonia concentrations were performed.

New method for cutting and shaping the ends of the PBGF was tested.

\section{Acknowledgement}

This research was supported by the Grant-in-Aid of Japanese Ministry of Ecology and Natural Resources. Authors would like to thank to Professor Lev Zimin, Mr. Yurij Zimin and Mr. Tatsuhiko Saitoh for fruitful advices and help during research work.

(Manuscript received Aug. 30, 2007, revised Jun. 4, 2008) 


\section{References}

(1) G. Pickrell and E. Smirnova : "Novel structures in random hole optical fibers", Proc. IEEE Sensors Conf., Irvine, California, 10. 1109/ICSENS. 2005. 1597801 (2005)

(2) C. Cordeiro, M. Franco, G. Chesini, E. Barretto, R. Lwin, C. Brito-Cruz, and M. Large : "Microstructured-core optical fibre for evanescent sensing applications", Opt. Express, Vol.14, pp.13056-13066 (2006)

(3) M. Yan : "Introduction to microstructured optical fibers", arXiv : physics/0508139v2 [physics.opticals], pp.1-19 (2005)

(4) J. Laesgaard and A. Bjarklev : "Microstructured optical fibers Fundamentals and applications", J. Am. Ceram. Soc., Vol.89, No.1, pp.2-12 (2006)

(5) P. Yeh, A. Yariv, and E. Marom : "Theory of Bragg fiber", J. Opt. Soc. Am., Vol.68, pp.1196-1201 (1978)

(6) T. Ueda and Y. Okamoto : "In Situ Status Measurement Technology", Proc. of $1^{\text {st }}$ Symposium on Advanced Photon Processing and Measurement Technologies, pp.25-28 (1998)

(7) T. Sugiyama, M. Wada, S. Nakajima, and T. Ueda : "High sensitivity In-situ Gas Measurement", Proc. of $4^{\text {th }}$ Workshop on Advanced Photon Processing and Measurement Technologies, pp.63-66 (2001)

(8) T. Sugiyama and T. Ueda : "In-situ Measurement for the Gas Concentrations Using Tunable Lasers", Proc. of Technical Meeting on Sensors and Micromachines, CHS-03-56, pp.1-4 (2003)

(9) J. Pawłat, T. Matsuo, T. Sugiyama, and T. Ueda : "Measurement of Low Gas Concentration Using Photonic Bandgap Fiber", J. Adv. Oxid. Technol., Vol.9, No.2, pp.150-155 (2006)

(10) J. Pawłat, T. Sugiyama, and T. Ueda : "In-situ Measurement of ppb Concentration of Gas", Proc. 22th Symp. Sensors, Micromachines and Appl. Syst. Tokyo, Japan, pp.279-284 (2005)

(11) T. Ritari, J. Tuominen, H. Ludvigsen, J. Petersen, T. Sørensen, T. Hansen, and H. Simonsen : "Gas sensing using air-guiding photonic bandgap fibers", Opt. Express, Vol.12, pp.4080-4087 (2004)

(12) M. Petrovich, A. VanBrakel, F. Poletti, K. Mukasa, E. Austin, V. Finazzi, P. Petropoulos, M. Watson, T. DelMonte, T. Monro, J. Dakin, and D. Richardson: "Microstructured fibres for sensing applications", Proc. SPIE Opticals East, Boston, USA, pp.15-29 (2005)

(13) D. Richardson, F. Poletti, J. Leong, X. Feng, H. Ebendorff-Heidepreim, V. Finazzi, K. Frampton, S. Asimakis, R. Moore, J. Baggett, J. Hayes, M. Petrovich, M. Tse, R. Amezcua, J. Price, N. Broderick, P. Petropoulos, and T. Monro : "Advances in microstructured fiber technology", Proc. IEEE/LEOS Workshop on Fibres and Optical Passive Components, USA, Institute of Electrical and Electronics Engineers, pp.1-9 (2005)

(14) L. Rothman, D. Jacquemart, A. Barbe, D. Benner, M. Birk, L. Brown, M. Carleer, C. Chackerian, K. Chance, L. Coudert, V. Dana, V. Devi, J. Flaud, R. Gamache, A. Goldman, J. Hartmann, K. Jucks, A. Maki, J. Mandin, S. Massie, J. Orphal, A. Perrin, C. Rinsland, M. Smith, J. Tennyson, R. Tolchenov, R. Toth, J. Vander Auwera, P. Varanasi, and G. Wagner : "The HITRAN 2004 molecular spectroscopic database”, J. of Quant. Spectr. Rad. Trans, Vol.96, No.2, pp.139-204 (2005)

(15) J. Pawłat, T. Sugiyama, T. Matsuo, and T. Ueda : "Photonic bandgap fiber for a sensing device", IEEJ Transactions on Sensors and Micromachines [E], Vol.127, No.3, pp.160-164 (2007)

(16) J. Pawłat, T. Matsuo, T. Sugiyama, and T. Ueda : "Possibility of Gas Concentration Measurement Using Photonic Crystal Fiber", Przeglad Elektrotechniczny (Poland), Vol.5, pp.31-35 (2007)

(17) Z. Huang : "Combining Ar ion milling with FIB lift-out techniques to prepare high quality site-specific TEM samples", J. Microscopy, Vol.215, No.3, pp.219-223 (2004)

Joanna Pawlat (Non-member) received her M. E and M. Sc. degree

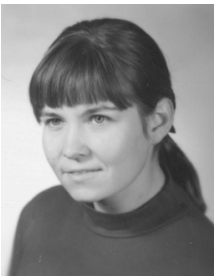

in Sanitary and Building Engineering in 1997 and in Environmental Protection in 1998, from Technical University of Lublin (Poland). She received D.Sc. degree from Saga University (Japan) on foaming phenomena in 2001. She was a post doctor researcher in the Department of Electrical and Electronic Engineering of Chuo University and JSPS research fellow in Saga University, cooperating with Toyohashi University. Presently, she is an assistant professor in Waseda University working on the gas sensing and foaming phenomena. She is a member of IEEE.
Tadashi Sugiyama (Non-member) received his B. E. degree in 1978

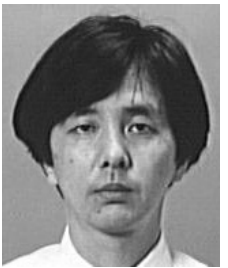
from Waseda University (Japan). He entered Yokogawa Electric Corporation in the same year and he is employed in the optical measurement systems application and development. He received Award from Society of Instrument and Control Engineers of Japan in 1988 and 1989. Mr. Sugiyama is a member of the Society of Instrument and Control Engineers of Japan and the Japan Society of Applied Physis.
Xuefeng Li

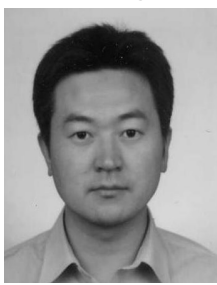

(Non-member) graduated from Shenyang Institute of Engineering (formerly Shenyang Electric Power Institute), China, in 1999. He received the M.E. and D.E. degree from Fukuoka Institute of Technology, Fukuoka, Japan, in 2004 and 2007, respectively. He is now a Visiting Research Associate of Waseda University. His research interest is simulation techniques of EM propagation, especially in optical wave propagation. $\mathrm{Dr}$. $\mathrm{Li}$ is a member of IEICE.
Takahiro Matsuo

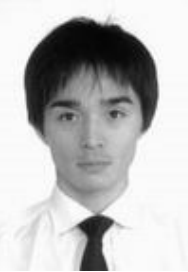

Satoshi Ikezawa

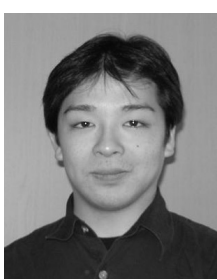

Toshitsugu Ueda

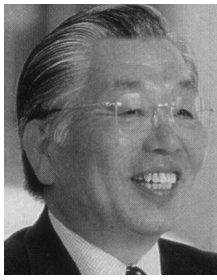

(Student Member) received his M. E degree in Electrical Engineering in 2001 from Saga University (Japan). He has worked in Rohm Apollo Device Co., Ltd. from 2001 to 2004 . He is currently working on $\mathrm{Ph} . \mathrm{D}$ degree at Graduate School of Information, Production and Systems in Waseda University while being an employee of Sakamoto Electric MFG.Co., Ltd.

(Student Member) was born in Saitama, Japan, on August 24, 1974. He received a B. A. degree Kitasato University in 1999. He received a Masters degree from Waseda University in 2006. above-mentioned technologies for temperature, pressure and displacement in Yokogawa Electric Corporation. Since 2003 he is a professor of Graduate School of Information, Production and Systems in Waseda University in Fukuoka (Japan), working on sensors and sensor systems. He received Awards from Society of Instrument and Control Engineers of Japan in 1987 and 1994, and Awards from Japan Institute Invention and Innovation in 1985 and 1987. Professor Ueda is a member of the Institute of Electrical Engineers of Japan, and Society of Instrument and Control Engineers of Japan. 